\title{
Determining optimal surgical care for patients with renal masses
}

\author{
Robert Abouassaly, MD, MSc, FRCSC
}

See related article on page 89 .

Cite as: Can Urol Assoc J 2011;5(2):96; D01:10.5489/cuaj.11046

$\mathrm{T}$ he recent literature has emphasized the importance of renal function on life expectancy and cardiovascular morbidity. This has been demonstrated in both the medical ${ }^{1}$ and surgical literature, ${ }^{2,3}$ and has led to the expansion of the indications for partial nephrectomy in treatment of renal masses. In fact, the American Urological Association guidelines for the management of clinical stage 1 renal masses recommend partial nephrectomy be considered the standard of care in tumours $<4 \mathrm{~cm}$ when judged to be technically feasible by a urologic surgeon. ${ }^{4}$

The current article evaluates the effect of warm ischemia time and other clinical variables on renal differential function measured by MAG3-lasix renal scintigraphy. ${ }^{5}$ They conclude that factors associated postoperative renal function were not the same before and after 30 minutes, and that the rate of functional loss increases significantly after 30 minutes. However, drawing any firm conclusions or altering clinical practice based on these findings may not be advisable. Firstly, this study assessed renal function as a median of 10 days after surgery, which is more reflective of acute kidney injury rather than long-term renal function. And it is likely that long-term renal function is of greater clinical importance. Secondly, this article is severely limited by its small sample size. Performing multivariable analyses with such small numbers risks overfitting the model, and is statistically inadvisable. Nonetheless, this article confirms the findings of others that renal functional loss is not linearly associated with warm ischemia at the time of partial nephrectomy, and that functional deterioration appears to accelerate with time. ${ }^{6}$ However, studies continue to find that any period of ischemia results in a negative effect on ultimate renal function. ${ }^{7}$
In summary, although level-1 evidence is lacking, observational studies suggest the importance of renal functional preservation in the treatment of small renal masses, which is best achieved with partial nephrectomy and minimization of renal ischemia when extirpation is deemed necessary. However, prospective, preferably randomized, studies are needed to more convincingly determine optimal surgical care in patients with renal masses.

Urological Institute, University Hospitals Case Medical Center, Cleveland, $\mathrm{OH}$

Competing interests: None declared.

This paper has been peer-reviewed.

\section{References}

1. Go AS, Chertow GM, Fan D, et al. Chronic kidney disease and the risks of death, cardiovascular events, and hospitalization. N Engl J Med 2004;351:1296-305.

2. Huang WC, Elkin EB, Levey AS, et al. Partial nephrectomy versus radical nephrectomy in patients with small renal tumors-is there a difference in mortality and cardiovascular outcomes? J Urol 2009; 181:55-61.

3. Thompson RH, Boorijan SA, Lohse CM, et al. Radical nephrectomy for pTla renal masses may be associated with decreased overall survival compared with partial nephrectomy. J Urol 2008;179:468-71.

4. Campbell SC, Novick AC, Belldegrun A et al. Guideline for management of the clinical Tl renal mass. J Urol 2009;182:1271-9.

5. Pouliot F, Pantuck A, Imbeault A, et al. Multivariate analysis of the factors involved in loss of renal differential function after laparoscopic partial nephrectomy: a role for warm ischemia time. Can Urol Assoc J 2011;5: 89-95; D0I:10.5489/cuaj.10044

6. Lane BR, Russo P, Uzzo RG, et al. Comparison of cold and warm ischemia during partial nephrectomy in 660 solitary kidneys reveals predominant role of nonmodifiable factors in determining ultimate renal function. J Urol 2011;185:421-7.

7. Thompson RH, Lane BR, Lohse $C M$, et al. Every minute counts when the renal hilum is clamped during partial nephrectomy. Eur Urol 2010;58:340-5.

Correspondence: Dr. Robert Abouassaly, Urological Institute, University Hospitals Case Medical Center 11100 Euclid Ave, Mailstop LKD 5046, Office 4565 Cleveland, OH 44106; fax: 216-844-1900; robert.abouassaly@UHhospitals.org 